\title{
Level of Actual Physical Fitness and its Perception among Students of Physiotherapy in Lahore
}

Tahir Mahmmod, Wajeeha Mahmood, Umer Maqsood, Abdul Salam, Nimra Sefat

\begin{abstract}
OBJECTIVE: To assess estimated and measured the physical fitness level of physiotherapy students. METHODOLOGY: This Cross sectional study carried out at Azra Naheed Medical College and School of Allied Health Sciences, Children Hospital Lahore, with Simple convenient sampling technique. The data was collected from 115 students including 42 male and 73 female, from $3^{\text {rd }}$ year to final year. Self-perceived fitness questionnaire was used for estimation of perceived fitness and actual physical fitness level was measured by common clinical tests. Harvard step was used for fitness index measurement. SPSS version $\mathbf{2 1 . 0}$ was used for analysis and Pearson correlation for the correlation of perceived and measured physical fitness level.

RESULTS: It was evident that physiotherapy students have good perception about their BMI. Results of perceived and measured body composition were correlated significantly .004 because they have good perception of body composition. Measured strength was low from the perceived, although some males were in average level. The results of strength show significant correlation for upper extremity that was 269 but for lower extremity non-significant. But measured flexibility results were good for lower extremities as compared to the shoulder flexibility for upper extremities, but both variables were different from perceived fitness. Actual fitness index level was very low as compared to the self-estimated.

CONCLUSION: Measured fitness was quite different from self-perceived. The students of physiotherapy were not physically fit as they perceived it. They need to improve their physical fitness level as their profession requires.
\end{abstract}

KEYWORDS: Physical Fitness, Perception, Physiotherapy Students, Lahore.

This article may be cited as: Mahmmod T, Mahmood W, Maqsood U, Salam A, Sefat N. Level of Actual Physical Fitness and its Perception among Students of Physiotherapy in Lahore. J Liaquat Uni Med Health Sci. 2019;18(01):60-4. doi: 10.22442/jlumhs.191810602

\section{INTRODUCTION}

Physical fitness is stated as the capability of body to work efficiently and effectively, to enjoy leisure, to be healthy, fight against disease, and to overcome with the emergency situations Physical fitness is considered as measure of almost near to all functions of our body (muscular, cardiovascular, nervous system and respiratory capacity, metabolic system and endocrinology of the body) important in the performing activities of routine ${ }^{1}$. Perception is the association, interpretation, and result of sensory information in order to respond and evaluation of the environment. Further, fitness can lead to improved perceptive working and can boost one's skill to take part in relaxation, often a nourishing social understanding. However, both health and wellness are much broader terms than physical fitness ${ }^{2}$. Physical fitness, accomplished by consistent workout and/or unstructured physical activity, discusses struggle by encouraging positive mental and physiological advantages, diminishing anxiety reactivity, protecting from possibly a number of long-lasting sicknesses ${ }^{3}$. It is the measure of optimal functioning of systems of the body particularly the cardiovascular, pulmonary, and musculoskeletal systems ${ }^{4}$. With the advancement of the world, as the machineries going advanced day by day, people are doing less work and this resulting in the decrease level of fitness ${ }^{5}$. The change of life style reduces levels of physical activity level. It is generally known that physical fitness level will be low if one take care about their motor skills and ignore the importance of fitness in human life $e^{6}$. This is why physical fitness is currently well-thought-out one of the vital indicators wellness of body and is also the interpreter of illness and death for cardiovascular system disorders and its causes. Studies of Huotari P $2009^{19}$ results stated that children and adolescents have consistent observations of their actual physical fitness level. In one of the study by Multani N $2013^{8}$, he measured that students were having poor endurance and strength but only $23 \%$ students were also underweight category of BMI, but they were good in measured flexibility and strength, but they perceived them to be fit as of their age fellows ${ }^{9}$. Studies by Jaakola T $2011^{7}$ found that Only $33 \%$ students were perceived their 
fitness as compared to actual. Studies do not focused on evaluation of actual and perceived fitness in the procedure of implementing the physical activity ${ }^{9}$. There is need to assess and interpret physical fitness of students for their own value and perfection. It can be tangibly and precisely evaluated by tests in the laboratory, but, cannot be used in population-based assessment because of the increase cost and time. Field-based tests deliver a sensible substitute instead of laboratory tests. Perceived fitness is defined as self -evaluation of fitness having four factors including, composition of body (it is the composition of the body according to the height and weight) cardio-vascular endurance (it is the capacity of body to sustain work without fatigue), muscular power(capacity of rate of doing wok in particular way) and muscular elasticity (the ability of body muscles to bend with ease) ${ }^{10}$, Previous studies if available were more emphasized on male students as compared to female students. Due to this, the aim of the study was to determine self-perceived and measured physical fitness of physiotherapy students. There was need of such study which can highlight importance of physical fitness for the students entering in physiotherapy profession. Further there was lack of studies regarding fitness level of physiotherapy students in Lahore.

\section{METHODOLOGY}

This cross sectional study was carried out at Azra Naheed Medical College and School of Allied Health Sciences, Children Hospital Lahore, with Simple convenient sampling technique after the approval from advance research committee, starting from October 2015 to March 2016. The data was collected from physical therapy institutes of Lahore including Azra Naheed Medical College and School of Allied Health Sciences, Children Hospital Lahore. Sample size was calculated as 127 margin of error $5 \%$ and confidence level of $95 \%$ with response distribution of $90 \%{ }^{12}$. Estimated population of physiotherapy students was 1500 in Lahore in 2015. The participants included were undergraduate students of physiotherapy, both male and female from $3^{\text {rd }}$ year to final year with age limit of 19 to 27 years. All the participants with any trauma (Minimum 6 months), any hereditary diseases and surgical limitation of range of motion were not included in the study. Firstly we measured the weight on weight machine and use tape for measurement of height of participants. Then weight in $\mathrm{kg}$ was divided by height in meters square as standard formula. BMI= (Weight in Kilograms)/(Height in Meters Square), then they were categorized in to BMI chart as; Underweight (Less than 18.5) Normal (more than 18.5), overweight (25-29) and obese (more than30) ${ }^{12}$.
Strength was measured with pushups for upper extremity and wall squat for lower extremity. For push-ups the subjects were asked to warm up and then by placing their both hands on the exercise mat with their feet comfortable in neutral position, with knee extended and whole body in straight line from head to heel, then they were asked to take their head toward ceiling with slowly extending the elbow to full extension. It was repeated till the subjects exhausted. According to Arnot and Gaines criteria we classified males as Excellent if they have scoring $>47$, good 39-47, above average 30-39, average 17-29, below average 10-16 and poor 4-9 and very poor < 4 similarly females were categorized separately as Excellent if they have scores $>36$, good $30-36$, above average 23-29, average 12-22, below average 7-11, Average 2-6 and Poor 0-1. Then they were categorized excellent, good, above average, average, below average and poor. For wall squat subjects were instructed to lift off the right foot while knee flexion 90 degree and back resting on wall and time was noted with help of stop watch and again same for the left foot, keeping the strength dominant factor in males we classified them accordingly. Then they were classified as Excellent $>102$ seconds above average $102-76$ seconds, average 75-58 seconds, below average 57-30 seconds, Poor $<30$ seconds (its male criteria), similarly females were also scored as excellent $>60$ second, above average 60-46 second, average 45-36 seconds, below average $35-20$ seconds, Poor $<20$ seconds ${ }^{14}$. The shoulder flexibility was used to measure the flexibility of upper extremity both the shoulders were assessed separately. Recorded overlap was scored from excellent to poor ${ }^{15}$. Toe-touch test was used for flexibility of lower extremity. The subjects were categorized as flexible if they were able to touch their toes and if unable to touch the toes, subjects were counted as non-flexible. Test reliability was $0.97^{15}$. Harvard Step test was used to measure their fitness index as endurance level. The equipment required were only a step of 20 inch $/ 50.8 \mathrm{~cm}$ in height and stop watch to calculate the time duration ${ }^{17}$. This is one of the best tests as its correlation to VO2 max was reported 0.6 to 0.8 in some studies. Simple convenient technique was used. First students were informed about the study before gathering data. The data provided by the participants was kept confidential. Keeping in view, data from female students was taken by female physiotherapist. The data was analyzed by using SPSS version 21.0. The statistical method used for correlation was the Pearson correlation for the perceived and measured physical fitness level. 
Tahir Mahmmod, Wajeeha Mahmood, Umer Maqsood, Abdul Salam, Nimra Sefat

\section{RESULTS}

All these results show that there was significant correlation of perceived body composition and measured BMI. The $\mathrm{p}$ value 0.006 for $\mathrm{BMI}$ and gender shows that association between these two variables. $46.5 \%$ females were in underweight category while males were only $19 \%$ in this category. BMI was normal $71 \%$ of males and $50.68 \%$ of females. While perceived BMI was near to the measured. The results of perceived fitness show that students were not well aware about their physical fitness level. As $43.83 \%$ of the students perceived their fitness level to be slightly below average of their age fellows but $71 \%$ students considered themselves as quite normal with regard to their age fellows. Only $20 \%$ categorized them as having well and $5.4 \%$ considered them as exceptionally fit. (Table I) Upper Extremity strength in male students was average and below average with $8.7 \%$ and $16.5 \%$ respectively. On the other side from 73 female students not a single female was in excellent category but $1.7 \%$ were in good category. These results were very different from estimated fitness (Table II). Lower Extremity measured strength of $3.4 \%$ of the males was in excellent Category as compared to females which were only $1.7 \%$.Most of the students were in below average category in which females were more as compared to males (Table III) . In measured upper extremity flexibility for left shoulder $26.19 \%$ ( 42) of males were in excellent category and females were $23.28 \%$ in this category, while $47.74 \%$ females were having good flexibility. These results were quite near to their perceived flexibility. Results of the lower extremities (toe-touch) were good. Out of 73 females 54 were flexible and 25 males out of 42 were flexible. On the other side 17 males were non-flexible and 19 females were non-flexible. These results show that the males were $59.52 \%$ were flexible as compared to females is $73.97 \%$. In perceived and measured flexibility, significant correlation was found between lower extremity but not for upper extremity flexibility. In fitness Index, no any single female was in the excellent and good category but only 3 males were in excellent and good category with percentage of $7.14 \%$ for each. Most of students were in the poor category. $88.5 \%$ of the students were exhausted before 5 minute of standard time.

When these strength tests were compared with the estimated, it was varying from the measured strength. The $P$ value 0.015 between fitness index and gender shows that there is significant association between these two variables (Table IV). During the proposal of this study we assumed a hypothesis that the perceived and measured physical fitness level was same in our participants, but we found that there was difference in the perception and actual measured fitness level in physiotherapy students.

TABLE II: UPPER EXTREMITY STRENGTH

\begin{tabular}{|l|c|r|}
\hline \multicolumn{1}{|c|}{ Category } & No. of students & \multicolumn{1}{c|}{ Percent } \\
\hline Male & $\mathbf{4 2}$ & $\mathbf{3 6 . \%}$ \\
\hline Excellent & 0 & 0 \\
\hline Good & 0 & 0 \\
\hline Above Average & 3 & 2.6 \\
\hline Average & 10 & 8.7 \\
\hline Below Average & 19 & 16.5 \\
\hline Poor & 9 & 7.8 \\
\hline Very Poor & 1 & 0.9 \\
\hline Female & $\mathbf{7 3}$ & $\mathbf{6 4 \%}$ \\
\hline Excellent & 0 & 0 \\
\hline Good & 2 & 1.7 \\
\hline Above Average & 0 & 0 \\
\hline Average & 4 & 3.5 \\
\hline Below Average & 17 & 14.8 \\
\hline Poor & 24 & 20.9 \\
\hline Very Poor & 26 & 22 \\
\hline Total & $\mathbf{1 1 5}$ & $\mathbf{1 0 0}$ \\
\hline
\end{tabular}

TABLE I: PERCEPTION OF PHYSICAL FITNESS LEVEL RESULT

\begin{tabular}{|c|c|c|c|c|c|}
\hline Scores & Fitness & Strength & Endurance & Flexibility & Body Composition \\
\hline 1 & 0 & 0 & 0 & 0 & 0 \\
\hline 3 & 7 & 17 & 12 & 5 & 10 \\
\hline 5 & 32 & 33 & 30 & 36 & 32 \\
\hline 7 & 52 & 35 & 54 & 44 & 43 \\
\hline 9 & 5 & 14 & 8 & 13 & 23 \\
\hline 11 & 15 & 14 & 9 & 14 & 4 \\
\hline 13 & 4 & 2 & 2 & 3 & 3 \\
\hline Total & $\mathbf{1 1 5}$ & $\mathbf{1 1 5}$ & $\mathbf{1 1 5}$ & $\mathbf{1 1 5}$ & $\mathbf{1 1 5}$ \\
\hline
\end{tabular}

*Scoring for self-perceived fitness 13 is for highest fitness component and 1 being the least one for all the variables of fitness. 
Level of Actual Physical Fitness and its Perception

TABLE III: LOWER EXTREMITY STRENGTH

\begin{tabular}{|l|c|r|}
\hline & Frequency & \multicolumn{1}{|c|}{ Percent } \\
\hline Male & $\mathbf{4 2}$ & $\mathbf{3 6 \%}$ \\
\hline Excellent & 4 & 3.5 \\
\hline Above Average & 5 & 4.3 \\
\hline Average & 2 & 1.7 \\
\hline Below Average & 13 & 11.3 \\
\hline Poor & 20 & 17.5 \\
\hline Female & $\mathbf{7 3}$ & $\mathbf{6 4 \%}$ \\
\hline Excellent & 2 & 1.7 \\
\hline Average & 3 & 2.6 \\
\hline Below Average & 18 & 15.7 \\
\hline Poor & 42 & 36.5 \\
\hline Unable to Perform & 6 & 5.2 \\
\hline Total & $\mathbf{1 1 5}$ & $\mathbf{1 0 0}$ \\
\hline
\end{tabular}

TABLE IV: FITNESS INDEX study which reveals results that students were less fit as compared to their self-estimated fitness. Study of Odebiyi D $2013^{4}$ in which males were significantly fit in terms of strength, speed, power and endurance then that of female in private and public Secondary Schools. However, the female students were significantly more agile than the male students. The results of present study also comparable to these results as these students participated from public and private sector but results of measured Strength and endurance as compared to self-estimated was different. Huotari P $2009^{18}$ find that there was high self -estimation of their fitness level as actually present in students ,but results of our study were different from this study in Finland because our students are not found to be aware of physical fitness level if we compare measures strength, flexibility and endurance level with perceived fitness. They were actually in poor category of endurance. Results of Hasalkar S $2005^{19}$ were same as the students were poor in physical fitness level. After these discussions we reached at the result that there is strong need to improve the fitness level of physiotherapy students.

\begin{tabular}{|c|c|c|c|c|c|c|c|}
\hline \multirow{2}{*}{\multicolumn{2}{|c|}{ Category }} & \multicolumn{5}{|c|}{ Fitness Index } & \multirow{3}{*}{$\begin{array}{c}\text { Total } \\
42\end{array}$} \\
\hline & & \multirow{2}{*}{$\frac{\text { Poor }<54}{33}$} & \multirow{2}{*}{$\frac{\text { 54-67 Low Average }}{1}$} & \multirow{2}{*}{$\frac{68-82 \text { Average }}{2}$} & \multirow{2}{*}{$\frac{83-96 \text { Good }}{3}$} & \multirow{2}{*}{$\frac{>96 \text { Excellent }}{3}$} & \\
\hline \multirow{2}{*}{ Gender } & Male & & & & & & \\
\hline & Female & 69 & 3 & 1 & 0 & 0 & 73 \\
\hline Total & & 102 & 4 & 3 & 3 & 3 & 115 \\
\hline
\end{tabular}

\section{DISCUSSION}

The result of this study shows that students were not well aware about their fitness level but were found to be conscious about the body composition. Students scored their perceived endurance level to be good, excellent and exceptional as well as some of them considered themselves in average but actual results were quite different from their perceived scoring. In one of the research correlation between self-perceived was significant for body composition, strength and flexibility ${ }^{8}$ but in our study correlation of BMI and composition is -.401 shows significant correlation. But result of perceived strength of Upper extremity -.269 that is significant in negative direction but lower extremity was different value -.159 that was nonsignificant compared to Multani N 2013. In another study in measured and perceived fitness, results showed that non athletic students were not aware about the fitness level. Perceived fitness score was higher than measured. Same is the result of present

\section{CONCLUSION}

It was concluded in this study that fitness level of students was not good in Lahore. They not even have awareness about their actual fitness level as required for the professional demands. There is need for the awareness campaign as well as proper assessment of the students before admission because the job demands and professional work demands for the physiotherapy students were different from other fields.

\section{LIMITATIONS}

Students were not willing to participate. We just analyzed the data of complete questionnaires only 115. The data was collected from Azra Naheed Medical College and School of Allied Health Sciences Children hospital Lahore, so further assessment is required in other physical therapy institutes to assess physical fitness level of the students. This study was not focused on residential location differences of the 
students as rural or urban backgrounds have a profound impact on the physical brought up and resultant fitness level of the students.

Conflict of Interest: There was no any conflict of interest.

Funding: There was no any funding agency.

\section{REFRENCES}

1. Jourkesh M, Sadri I, Ojagi A, Sharanavard A. Comparison of Physical fitness level among the students of IAU, Shabestar Branch. Annals of Biological Research. 2011; 2(2): 460-7.

2. Paoli A, Bianco A. What is fitness training? Definitions and implications: A systematic review article. Iran J Public Health. 2015; 44(5):602-14.

3. Silverman MN, Deuster PA. Biological mechanisms underlying the role of physical fitness in health and resilience. Interface focus. 2014; 4 (5):20140040. doi: 10.1098/rsfs.2014.0040.

4. Odebiyi D. Comparison of Physical Fitness Level of Private and Public Secondary School Students in a Nigerian Population: A Preliminary Study. UNILAG Journal Basic Medical Sciences. 2013; 1 (1):1-3.

5. Hian TC, Mahmud ZF, Choong TY. Physical fitness level between Urban and Rural Students-Case study. Procedia-Social and Behavioral Sciences. 2013; 90:847-52. doi: 10.1016/j.sbspro.2013.07.160.

6. Kotwica A, Majcher P. Physical fitness level of 1st year medicine and physiotherapy students of Lublin Medical University. Pol J Sport Tourism. 2012; 19(2):107-12. doi: 10.2478/v10197-012-00011-4.

7. Jaakkola T, Washington TL. Measured and perceived physical fitness, intention, and self-reported physical activity in adolescence. Advances in Physical Education. 2011; 1(02):1622. doi: 10.4236/ape.2011.12004.

8. Multani N, Singh A. Level of physical fitness among physiotherapy students a study of Punjab and Haryana. 2013; 21:1136-40. doi: 10.5829/ idosi.wasj.2013.21.8.1839.

AUTHOR AFFILIATION:

\section{Tahir Mahmood (Corresponding Author)}

Lecturer

Department of Bahawalpur Institute of Rehabilitation Sciences

Bahawalpur Medical and Dental College

Bahawalpur, Punjab-Pakistan.

Email: dr.tahir11344@gmail.com

\section{Wajeeha Mahmood}

Senior Lecturer, Department of Physical Therapy

Azra Naheed Medical College

Superior University Lahore, Punjab-Pakistan.
9. Hasalkar S, Shivalli R, Biradar N. Measures and physical fitness level of the college going student. Anthropologist. 2005; 7(3):185-7.

10. Kuosmanen K, Rovio S, Kivipelto M, Tuomilehto $J$, Nissinen A. Determinants of Self-Rated Health and Self-Rated Physical Fitness in Middle and Old Age. Eur J Mental Health. 2016; 11(1-2): 128-43.

11. Raosoft I. Sample size calculator. Available from: www.raosoft com/samplesize.

12. U.S Preventive Sevices Task Force. Screening for obesity in adults: recommendations and rationale. Ann Intern Med. 2003;139(11):930-2.

13. Berhanu F. Comparative Analysis between Project Participants and Non Participants in some Trining Qualities of Football with Reference to Kirkos Sub-City. [Published Thesis]. AAU Intstitutional Repository. 2015.

14. Kraus E, Eisenmenger-Weber S. Evaluation of posture based on structural and functional measurements. Phys Ther Rev. 1045; 25:267-71.

15. Kippers V, Parker AW. Toe-touch test: a measure of its validity. Phys Ther. 1987; 67(11):1680-4.

16. Skubic V, Hodgkins J. Cardiovascular efficiency test for girls and women. Research Quarterly. American Association for Health, Physical Education and Recreation. 1963; 34(2):191-8. doi:10.1080/ 10671188.1963.10762129

17. Hoseini R, Rahmani-nia F, Azizi M. Analysis of the Relationship between Self-estimated and Measured Physical Fitness among Non-athletic Female and Male University Students. ZUMSJ. 2012; 20(79):83-93.

18. Huotari $P$, Sääkslahti $A$, Watt $A$. Associations between the self-estimated and actual physical fitness scores of Finnish Grade 6 students. Facta Universitatis: Series Physical Education and Sport. 2009; 7(1):27-36.

19. Hasalkar S, Shivalli R, Biradar N. Measures and physical fitness level of the college going students. Anthropologist. 2005; 7(3):185-7. doi: 10.1080/09720073.2005.11890904.

\section{Umer Maqsood}

Assistant Professor, Department of Physical Therapy Azra Naheed Medical College

Superior University Lahore, Punjab-Pakistan.

\section{Abdul Salam}

Assistant Professor, Department of Physical Therapy Sahara Medical College, Narowal, Punjab-Pakistan.

\section{Nimra Sefat}

Student, Department of Physical Therapy

Children Hospital Lahore, Punjab-Pakistan. 